\title{
Baseline fragmented QRS increases the risk of major arrhythmic events in Brugada syndrome: Systematic review and meta-analysis
}

\author{
Pattara Rattanawong MD ${ }^{1,2}$ (D) | Tanawan Riangwiwat MD $^{1}$ | Narut Prasitlumkum \\ $M^{1}$ | Nath Limpruttidham MD, MPH $^{1}$ | Napatt Kanjanahattakij MD ${ }^{3}$ | \\ Pakawat Chongsathidkiet MD ${ }^{4}$ Wasawat Vutthikraivit MD $^{5}$ | \\ Eugene H. Chung MD, FHRS, FAHA, FACC ${ }^{6}$
}

\footnotetext{
${ }^{1}$ University of Hawaii Internal Medicine Residency Program, Honolulu, HI, USA

${ }^{2}$ Faculty of Medicine Ramathibodi Hospital, Mahidol University, Bangkok, Thailand

${ }^{3}$ Department of Medicine, Einstein Medical Center, Philadelphia, PA, USA

${ }^{4}$ Department of Pathology, Duke University Medical Center, Durham, NC, USA

${ }^{5}$ Department of Medicine, Texas Tech University Health Sciences Center, Lubbock, Tx, USA

${ }^{6}$ Department of Internal Medicine, University of Michigan Medical School, Michigan

Medicine, Ann Arbor, MI, USA

Correspondence

Pattara Rattanawong, MD, University of Hawaii Internal Medicine Residency Program, Honolulu, HI, USA.

Email: pattarar@hawaii.edu
}

Background: Fragmented QRS reflects disturbances in the myocardium predisposing the heart to ventricular tachyarrhythmias. Recent studies suggest that fragmented QRS (fQRS) is associated with major arrhythmic events in Brugada syndrome. However, a systematic review and meta-analysis of the literature has not been done. We assessed the association between fQRS and major arrhythmic events in Brugada syndrome by a systematic review of the literature and a meta-analysis.

Methods: We comprehensively searched the databases of MEDLINE and EMBASE from inception to May 2017. Included studies were published prospective or retrospective cohort studies that compared major arrhythmic events (ventricular fibrillation, sustained ventricular tachycardia, sudden cardiac arrest, or sudden cardiac death) in Brugada syndrome with fQRS versus normal QRS. Data from each study were combined using the random-effects, generic inverse variance method of DerSimonian and Laird to calculate risk ratios and $95 \%$ confidence intervals.

Results: Nine studies from January 2012 to May 2017 were included in this metaanalysis involving 2,360 subjects with Brugada syndrome (550 fQRS and 1,810 nonfQRS). Fragmented QRS was associated with major arrhythmic events (pooled risk ratio $=3.36,95 \%$ confidence interval: $2.09-5.38, p<.001, l^{2}=50.9 \%$ ) as well as fatal arrhythmia (pooled risk ratio $=3.09,95 \%$ confidence interval: $1.40-6.86, p=.005$, $\left.1^{2}=69.7 \%\right)$.

Conclusions: Baseline fQRS increased major arrhythmic events up to 3-fold. Our study suggests that fQRS could be an important tool for risk assessment in patients with Brugada syndrome.

KEYWORDS

Brugada syndrome, fragmented QRS, sudden cardiac death 


\section{1 | INTRODUCTION}

Brugada syndrome is characterized by a type 1 coved-pattern electrocardiogram (ECG) in the right precordial leads in patients without apparent structural heart abnormalities. The disease increases the risk of ventricular arrhythmias and sudden cardiac death (SCD) (Brugada \& Brugada, 1992). However, risk stratification of Brugada syndrome remains unclear leading to a clinical challenge (Adler et al., 2016). A history of cardiac arrest is a strong predictor of recurrent ventricular fibrillation (VF) up to 35\%-48\% at 4-10 years (Probst et al., 2010; Sacher et al., 2013). Malignant syncope is considered as a moderate predictor of spontaneous VF (Probst et al., 2010), whereas familial sudden cardiac death and the presence of a SCN5A mutation is less well-defined prognostic value (Adler et al., 2016). For the ECG risk stratification, the presence of spontaneous type I ECG increases the risk for VF in all previous multivariate analysis studies (Delise et al., 2011; Priori et al., 2012; Probst et al., 2010). Fragmented QRS (fQRS) has been reported as potential noninvasive tool for risk stratification in various cardiac conditions (Das \& Zipes, 2009). In Brugada syndrome, the presence of fQRS correlates with increased risk in most of the studies (de Asmundis et al., 2017; Maury et al., 2013; Morita et al., 2008, 2017; Priori et al., 2012; Take et al., 2012; Tokioka et al., 2014). However, several studies did not show significant correlation (Conte et al., 2016; Sakamoto et al., 2016) thus the role of fQRS has been controversial (Adler et al., 2016). We performed a meta-analysis to assess the predictive value of fQRS in precordial leads $\left(V_{1}-V_{3}\right)$ for the development of major arrhythmic events (MAE) in Brugada syndrome patient.

\section{2 | METHODS}

\section{1 | Search strategy}

Two investigators (NP and NL) independently searched for published studies indexed in MEDLINE and EMBASE databases from inception to June 2017 using a search strategy (Figure 1) that included the terms for "fragmented QRS," "QRS fragmentation," and "Brugada." Only English language publications were included. A manual search for additional pertinent studies and review articles using references from retrieved articles was also completed.

\section{2 | Inclusion criteria}

The eligibility criteria included the following:

1. Cohort study (prospective or retrospective) reporting incident of major arrhythmic events (MAE) including VF, sustained ventricular tachycardia (sVT), sudden cardiac arrest, or sudden cardiac death, in Brugada syndrome patient with and without fQRS.

2. Relative risk, hazard ratio, odds ratio, incidence ratio, or standardized incidence ratio with $95 \%$ confidence intervals or sufficient raw data for the calculation were provided.
3. Brugada syndrome participants without fQRS were used as controls.

Study eligibility was independently determined by two investigators (NK and PC) and differences were resolved by mutual consensus. Newcastle-Ottawa quality assessment scale was used to evaluate each study in three domains: recruitment and selection of the participants, similarity and comparability between the groups, and ascertainment of the outcome of interest among cohort studies (Stang, 2010).

\section{3 | Data extraction}

A standardized data collection form was used to obtain the following information from each study: title of study, name of first author, year of study, year of publication, country of origin, number of participants, demographic data of participants, method used to identify cases and controls, method used to diagnose the outcomes of interest (fQRS and major arrhythmic events), and average duration of follow-up with confounders that were adjusted and adjusted effect estimates with $95 \%$ confidence intervals $(\mathrm{Cl})$ and covariates that were adjusted in the multivariable analysis.

To ensure accuracy, all investigators independently performed this data extraction process. Any data discrepancy was resolved by referring back to the original articles.

\subsection{Statistical analysis}

We performed a meta-analysis of the included cohort studies using a random-effects model. The extracted studies were excluded from the analysis if they did not present an outcome in each intervention group or did not have enough information required for continuous data comparison. We pooled the point estimates from each study using the generic inverse-variance method of DerSimonian and Laird (1986). The heterogeneity of effect size estimates across these studies was quantified using the $I^{2}$ statistic and Q statistic. For the Q statistic, substantial heterogeneity was defined as $p<.10$. The $I^{2}$ statistic ranges in value from $0 \%$ to $100 \%\left(I^{2}<25 \%\right.$, low heterogeneity; $l^{2}=25 \%-50 \%$, moderate heterogeneity; and $I^{2}>50 \%$, substantial heterogeneity) (Higgins, Thompson, Deeks, \& Altman, 2003). A sensitivity analysis was performed to assess the influence of the individual studies on the overall results by omitting one study at a time. Publication bias was assessed using funnel plot and Egger's regression test (Sterne \& Egger, 2001) ( $p$ <.05 was considered significant). All data analyses were performed using the Stata SE 14.1 software from StataCorp LP.

\section{5 | Sensitivity analysis}

We used a sequential exclusion strategy, as described by Patsopoulos and colleagues, to examine whether overall estimates were influenced by the substantial heterogeneity observed (Patsopoulos, Evangelou, \& loannidis, 2008). We sequentially and cumulatively excluded studies that accounted for the largest share of heterogeneity until $I^{2}$ was 


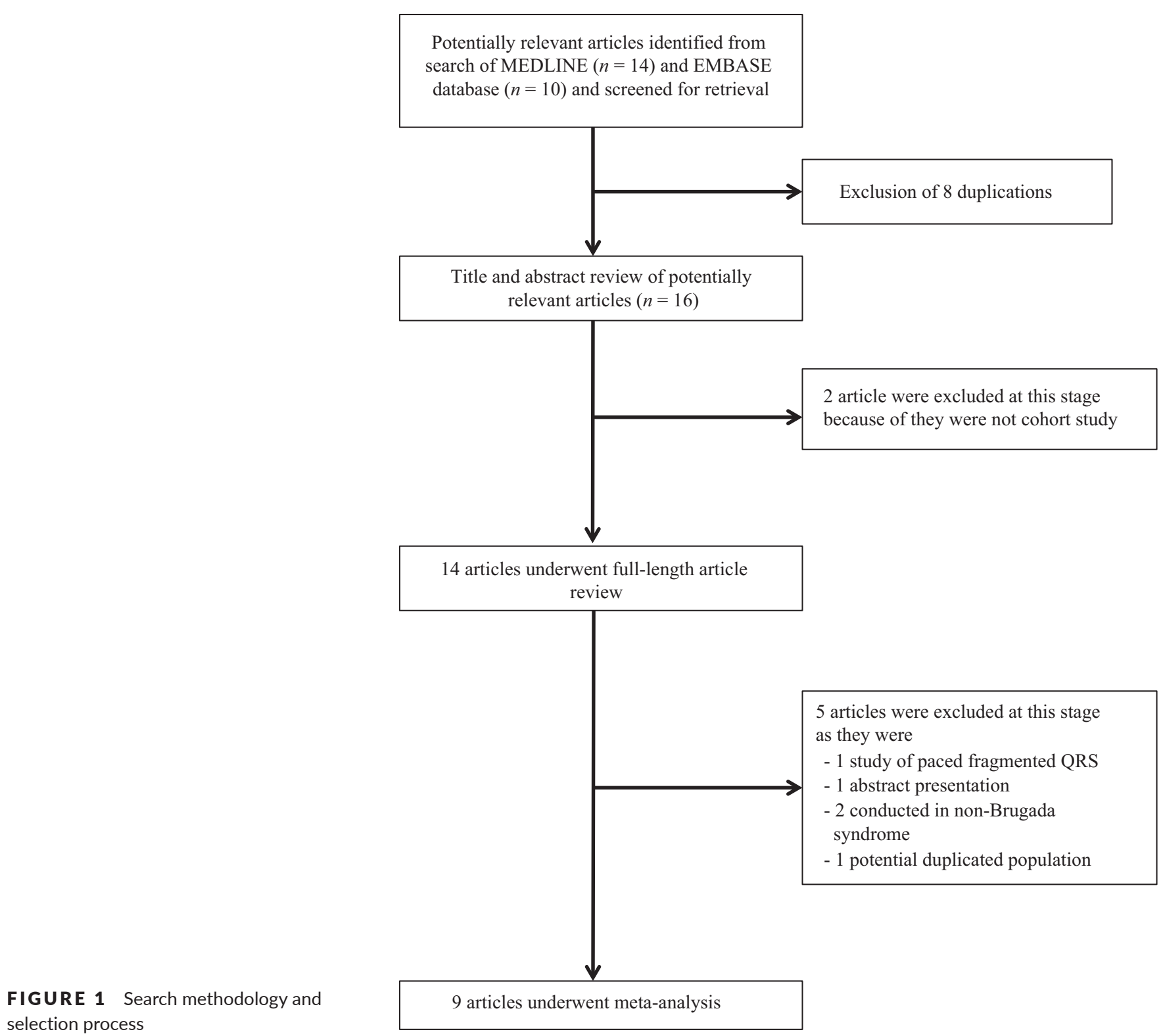

FIGURE 1 Search methodology and selection process arch of MEDLINE $(n=14)$ and EMBASE database $(n=10)$ and screened for retrieval
Title and abstract review of potentially relevant articles $(n=16)$ because of they were not cohort study less than $50 \%$. We then examined whether relative risk estimates were consistent. In accordance with Cochrane, evidence of publication bias was examined through funnel plots if there were more than 10 available studies. Funnel plot asymmetry was further confirmed with Egger's test. If asymmetry was present, we used the trim-and-fill method to adjust for publication bias. Potential bias from clinical characteristics were analyzed with subgroup analysis and were compared with meta-regression among European versus Japanese descendants, case-control versus cohort study design, and univariate versus multivariate analysis.

\section{3 | RESULTS}

\section{1 | Description of included studies}

Our search strategy yielded 24 potentially relevant articles (10 articles from EMBASE and 14 articles from MEDLINE). After exclusion of 8 duplicated articles, 16 articles underwent title and abstract review. Two were excluded at this stage since they were not cohort studies, leaving 14 articles for full-length article review. Five studies were excluded: 1 abstract presentation, 1 potential duplicated studied population, 2 conducted in non-Brugada syndrome patients, 1 study of paced fQRS. Therefore, four retrospective and five prospective cohort studies with 550 fQRS and 1,810 non-fQRS Brugada syndrome pateints were included in this meta-analysis. The clinical characteristics are described in Table 1.

\subsection{Quality assessment of included studies}

The Newcastle-Ottawa scale (zero to nine) was used to evaluate included studies on three domains: selection, comparability, and outcomes. Higher scores represent higher study quality. The score of each study ranged from seven to nine which reflected the high quality of included studies. Intrastudy risks of bias including study 
TAB LE 1 The clinical characteristics and summary of included studies

\begin{tabular}{|c|c|c|c|c|c|c|}
\hline First author & $\begin{array}{l}\text { Country of } \\
\text { origin }\end{array}$ & Year & Study type & Participant description & Exclusion criteria & Total population \\
\hline $\begin{array}{l}\text { de Asmundis } \\
\text { et al. }\end{array}$ & Belgium & 2017 & $\begin{array}{l}\text { Prospective } \\
\text { cohort study }\end{array}$ & $\begin{array}{l}\text { Spontaneous or drug } \\
\text { induced type } 1 \text { Brugada } \\
\text { pattern ECG }\end{array}$ & $\begin{array}{l}\text { Underlying structural } \\
\text { cardiac abnormalities }\end{array}$ & 289 \\
\hline Calò et al. & Italy & 2016 & $\begin{array}{l}\text { Prospective } \\
\text { cohort study }\end{array}$ & $\begin{array}{l}\text { Spontaneous type } 1 \text { Brugada } \\
\text { pattern ECG }\end{array}$ & $\begin{array}{l}\text { History of VF or aborted } \\
\text { SCD }\end{array}$ & 347 \\
\hline Conte et al. & Belgium & 2016 & $\begin{array}{l}\text { Prospective } \\
\text { cohort study }\end{array}$ & $\begin{array}{l}\text { Spontaneous or drug } \\
\text { induced type } 1 \text { Brugada } \\
\text { pattern ECG who } \\
\text { underwent ICD therapy }\end{array}$ & $\begin{array}{l}\text { Underlying structural } \\
\text { cardiac abnormalities }\end{array}$ & 176 \\
\hline Maury et al. & France & 2013 & $\begin{array}{l}\text { Retrospective } \\
\text { cohort study }\end{array}$ & $\begin{array}{l}\text { Spontaneous or drug } \\
\text { induced type } 1 \text { Brugada } \\
\text { pattern ECG }\end{array}$ & $\mathrm{N} / \mathrm{A}$ & 325 \\
\hline Morita et at. & Japan & 2017 & $\begin{array}{l}\text { Retrospective } \\
\text { cohort study }\end{array}$ & $\begin{array}{l}\text { Spontaneous type } 1 \text { Brugada } \\
\text { pattern ECG }\end{array}$ & $\begin{array}{l}\text { Low quality of ECG } \\
\text { recording and lack of ECG } \\
\text { recording of } V_{1} \text { and } V_{2}\end{array}$ & 456 \\
\hline Priori et al. & Italy & 2012 & $\begin{array}{l}\text { Prospective } \\
\text { cohort study }\end{array}$ & $\begin{array}{l}\text { Patients } \geq 18 \text { years old with } \\
\text { spontaneous or drug } \\
\text { induced type } 1 \text { Brugada } \\
\text { pattern ECG who never } \\
\text { had cardiac arrest and sVT }\end{array}$ & $\begin{array}{l}\text { Structural cardiac } \\
\text { abnormalities or cardiac } \\
\text { diseases }\end{array}$ & 308 \\
\hline Sakamoto et al. & Japan & 2015 & $\begin{array}{l}\text { Case-control } \\
\text { study }\end{array}$ & $\begin{array}{l}\text { Spontaneous or drug } \\
\text { induced type } 1 \text { Brugada } \\
\text { pattern ECG }\end{array}$ & $\begin{array}{l}\text { Taking antiarrhythmic } \\
\text { drugs, abnormality in } \\
\text { either the right or left } \\
\text { ventricular morphology } \\
\text { and/or function }\end{array}$ & 129 \\
\hline Take et al. & Japan & 2012 & $\begin{array}{l}\text { Retrospective } \\
\text { cohort study }\end{array}$ & $\begin{array}{l}\text { Spontaneous or drug } \\
\text { induced type } 1 \text { Brugada } \\
\text { pattern ECG with history of } \\
\text { syncope }\end{array}$ & $\begin{array}{l}\text { History of VF due to } \\
\text { ischemic heart disease }\end{array}$ & 84 \\
\hline Tokioka et al. & Japan & 2014 & $\begin{array}{l}\text { Retrospective } \\
\text { cohort study }\end{array}$ & $\begin{array}{l}\text { Spontaneous or drug } \\
\text { induced type } 1 \text { Brugada } \\
\text { pattern ECG }\end{array}$ & $\mathrm{N} / \mathrm{A}$ & 246 \\
\hline
\end{tabular}

ECG, electrocardiogram; ERP, early repolarization pattern; fQRS, fragmented QRS; ICD, implantable cardioverter defibrillator; N/A, not applicable; SCD, sudden cardiac death; SD, sudden death; SVT, sustained ventricular tachycardia; VF, ventricular tachycardia.

population definition, outcome definition, independent assessment of the outcome, follow-up duration, selective loss during follow-up, and identified limitation, were evaluated for each included study and no intrastudy risk of bias was identified.

\section{3 | Meta-analysis results}

Nine studies (550 fQRS and 1,810 non-fQRS) were included. Every study revealed an increased risk of MAE (VF, sVT, SCA, or SCD) in Brugada syndrome patients with seven meeting statistical significance (de Asmundis et al., 2017; Maury et al., 2013; Morita et al., 2008, 2017; Priori et al., 2012; Take et al., 2012; Tokioka et al., 2014). However, two studies did not show significant association (Conte et al., 2016; Sakamoto et al., 2016). In our meta-analysis,
fQRS in the precordial leads was significantly associated with the primary outcome of MAE (risk ratio $[R R]=3.36 \%, 95 \% \mathrm{Cl}$ : 2.09 5.38, $p<.001, l^{2}=50.9 \%$ ) (Figure 2). To evaluate a subgroup of fatal arrhythmia (VF, sVT, and appropriate shock) as an outcome, there were five studies (248 fQRS and 905 non-fQRS) which only reported fatal arrhythmia: all five studies revealed an increased risk of fatal arrhythmia among patients with fQRS with three achieving statistical significance (Morita et al., 2017; Priori et al., 2012; Take et al., 2012). The pooled analysis of the secondary outcome demonstrated a statistically significant increased risk of fatal arrhythmia in patients with fQRS (RR $=3.09 \%, 95 \% \mathrm{Cl}$ : 1.40-6.86, $p=.005, l^{2}=69.7 \%$ ) (Figure 2). The statistical heterogeneity was substantial with $I^{2}$ of $50.9 \%$ and $69.7 \%$ for the primary and secondary outcomes respectively. No publication bias was found from 


\begin{tabular}{|c|c|c|c|c|c|c|}
\hline $\begin{array}{l}\text { Male } \\
(\%)\end{array}$ & $\begin{array}{l}\text { Mean age } \\
\text { (years) }\end{array}$ & fQRS definition & $\begin{array}{l}\text { fQRS } \\
\text { (n) }\end{array}$ & $\begin{array}{l}\text { Mean duration of } \\
\text { follow-up } \\
\text { (months) }\end{array}$ & $\begin{array}{l}\text { Outcome } \\
\text { definition }\end{array}$ & Conclusion by authors \\
\hline 70 & $45 \pm 16$ & $\begin{array}{l}\text { Abnormal fragmentation within the QRS } \\
\text { complex as } \geq 4 \text { spikes in I or } \geq 8 \text { spikes in } V_{1} \text {, } \\
V_{2} \text {, and } V_{3}\end{array}$ & 50 & $121.2 \pm 55.2$ & VF or SCD & $\begin{array}{l}\text { fQRS was associated } \\
\text { with VF/SCD }\end{array}$ \\
\hline 78.4 & $45 \pm 13.1$ & $\begin{array}{l}\text { Fragmentation within the QRS complex, with } \\
\geq 4 \text { spikes in a single lead or } \geq 8 \text { spikes in } V_{1} \text {, } \\
V_{2} \text {, and } V_{3}\end{array}$ & 85 & $48 \pm 38$ & VF or SCD & $\begin{array}{l}\text { fQRS was associated } \\
\text { with VF/SCD }\end{array}$ \\
\hline 67 & $40.7 \pm 16.7$ & $\begin{array}{l}\text { Abnormal fragmentation within the QRS } \\
\text { complex as } \geq 4 \text { spikes in I or } \geq 8 \text { spikes in } V_{1} \text {, } \\
V_{2} \text {, and } V_{3}\end{array}$ & 29 & $95.2 \pm 51.10$ & $\begin{array}{l}\text { Appropriate } \\
\text { ICD shock } \\
\text { to VF/sVT }\end{array}$ & $\begin{array}{l}\text { fQRS was not } \\
\text { associated with a } \\
\text { higher rate of } \\
\text { appropriate ICD shock }\end{array}$ \\
\hline 79.4 & $47 \pm 13$ & Fragmented $\mathrm{QRS}$ in $\mathrm{V}_{1}$ to $\mathrm{V}_{3}$ & 8 & $48 \pm 34$ & SD & $\begin{array}{l}\text { fQRS was associated } \\
\text { with SDs }\end{array}$ \\
\hline 95 & $46.5 \pm 14$ & $\begin{array}{l}\text { (1) } \geq 4 \text { positive spikes in one of the leads } V_{1} \\
\text { through } V_{3} \text { or }(2) \geq 8 \text { positive spikes in all of } \\
V_{1}, V_{2} \text {, and } V_{3}\end{array}$ & 229 & $89.5 \pm 62.1$ & VF & $\begin{array}{l}\text { Patients with fQRS had } \\
\text { a shorter time to } \\
\text { arrhythmic events }\end{array}$ \\
\hline 80 & $45 \pm 12$ & $\geq 2$ spikes within the QRS complex in $\mathrm{V}_{1}$ to $\mathrm{V}_{3}$ & 25 & $36 \pm 8$ & $\begin{array}{l}\text { VF or } \\
\text { appropriate } \\
\text { ICD }\end{array}$ & $\begin{array}{l}\text { fQRS was associated } \\
\text { with arrthymia events }\end{array}$ \\
\hline 94.6 & $52 \pm 12$ & $\begin{array}{l}\text { (1) } \geq 4 \text { positive spikes in one of the leads } V_{1} \\
\text { through } V_{3} \text { or }(2) \geq 8 \text { positive spikes in all of } \\
V_{1}, V_{2} \text {, and } V_{3}\end{array}$ & 9 & 49.24 & VF & $\begin{array}{l}\text { fQRS was not } \\
\text { associated VF }\end{array}$ \\
\hline 97.6 & $47 \pm 12$ & Fragmented $\mathrm{QRS}$ in $\mathrm{V}_{1}$ to $\mathrm{V}_{3}$ & 37 & $48 \pm 48$ & $\begin{array}{l}\text { VF or } \\
\text { appropriate } \\
\text { ICD }\end{array}$ & $\begin{array}{l}\text { fQRS was associated } \\
\text { with the occurrence of } \\
\text { VF }\end{array}$ \\
\hline 95.9 & $47.6 \pm 13.6$ & $\begin{array}{l}\text { Abnormal fragmentation within the QRS } \\
\text { complex as } \geq 4 \text { spikes in I or } \geq 8 \text { spikes in } V_{1} \text {, } \\
V_{2} \text {, and } V_{3}\end{array}$ & 78 & $45.1 \pm 44.3$ & VF or SCD & $\begin{array}{l}\text { VF/SCD episodes were } \\
\text { more frequently } \\
\text { observed in patients } \\
\text { with fQRS than in } \\
\text { those without fQRS }\end{array}$ \\
\hline
\end{tabular}

Egger test (data not shown) and funnel plot (Figure 3). Sensitivity analysis to explore heterogeneity showed no significant change in our findings when omitting each study. Cumulative analysis indicated no substantial variation in RR by publication date. For exploratory subgroup analysis, we found no difference among European versus Japanese descendants $(p=.751)$, case-control versus cohort study design $(p=.431)$, and univariate versus multivariate analysis $(p=.801)$.

\section{4 | DISCUSSION}

Brugada syndrome is an inherited arrhythmic heart disease which increases the risk of ventricular arrhythmias and SCD (Brugada \&
Brugada, 1992). Recommended prevention strategies include exercise restriction, avoidance of excessive alcohol intake, anti-arrhythmic drugs, and implantable cardioverter defibrillator (ICD) (Priori et al., 2015). Identifying those who would benefit from ICD is challenging but an essential part of clinical decision making. Since there is no randomized control trials or strong evidence that can be used to help decide on ICD implantation in Brugada syndrome patients, recommendations are based on cohort studies which provide relationship between clinical characteristics and prognostic outcomes.

A history of cardiac arrest (Probst et al., 2010; Sacher et al., 2013), spontaneous type I ECG (Delise et al., 2011; Priori et al., 2012; Probst et al., 2010), and malignant syncope (Probst et al., 2010) are wellestablished significant prognosis predictors of MAE in Brugada syndrome. Fragmented QRS (fQRS) has also been reported as a potential 


\section{Major arrhythmic events}

\begin{tabular}{|c|c|c|c|}
\hline Study, years & & $\operatorname{RR}(95 \% \mathrm{Cl})$ & Weight $\%$ \\
\hline de Asmundis et al. 2017 & $\frac{1}{1}$ & $6.33(2.35,17.07)$ & 11.49 \\
\hline Calò, 2016 & $\rightarrow \quad 1$ & $1.90(0.88,4.09)$ & 14.42 \\
\hline Conte et al. 2016 & + & $1.18(0.52,2.68)$ & 13.68 \\
\hline Muary et al. 2013 & $\rightarrow$ & $7.93(2.06,30.49)$ & 8.05 \\
\hline Morita et al. 2017 & & $5.84(2.89,11.82)$ & 15.33 \\
\hline Priori et al. 2012 & 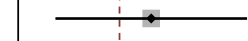 & $4.90(1.56,15.40)$ & 9.84 \\
\hline Sakamoto et al. 2016 & & $1.14(0.11,12.27)$ & 3.38 \\
\hline Take et al. 2012 & $\rightarrow$ & $2.39(1.06,5.38)$ & 13.80 \\
\hline Takioka et al. 2014 & & $5.21(1.69,16.09)$ & 10.00 \\
\hline $\begin{array}{l}\text { Overall } \\
\text { Heterogeneity chi-squared }=16.29(d f=8), p=.038 \\
\text { l-squaredd }=50.9 \% \\
\text { Estimate of between-study variance Tau-squared }=0.2505 \\
z=5.02, p=.000\end{array}$ & & $3.36(2.09,5.38)$ & 100.00 \\
\hline .1 & 10 & & \\
\hline Fatal arrhythmias & & & \\
\hline Study, years & & $\mathrm{RR}(95 \% \mathrm{Cl})$ & Weight $\%$ \\
\hline Conte et al. 2016 & $\rightarrow$ & $1.18(0.52,2.68)$ & 23.39 \\
\hline Morita et al. 2017 & - & $5.84(2.89,11.82)$ & 25.01 \\
\hline Priori et al. 2012 & $\leftrightarrow$ & $\rightarrow 8.90(3.04,26.04)$ & 19.86 \\
\hline Sakamoto et al. 2016 & & $1.14(0.11,12.27)$ & 8.24 \\
\hline Take et al. 2012 & & $2.39(1.06,5.38)$ & 23.51 \\
\hline $\begin{array}{l}\text { Overall } \\
\text { Heterogeneity chi-squared }=13.19(d f=4), p=0.010 \\
l \text {-squared }=69.7 \% \\
\text { Estimate of between-study variance Tau-squared }=0.5292 \\
z=2.78, p=0.005\end{array}$ & & $3.09(1.40,6.86)$ & 100.00 \\
\hline .1 & 10 & & \\
\hline
\end{tabular}

FIGURE 2 Forest plot of the included studies assessing the association between fragmented QRS and major arrhythmic events and fatal arrhythmia

*Note: RR; Risk Ratio, Cl; Confidence Interval

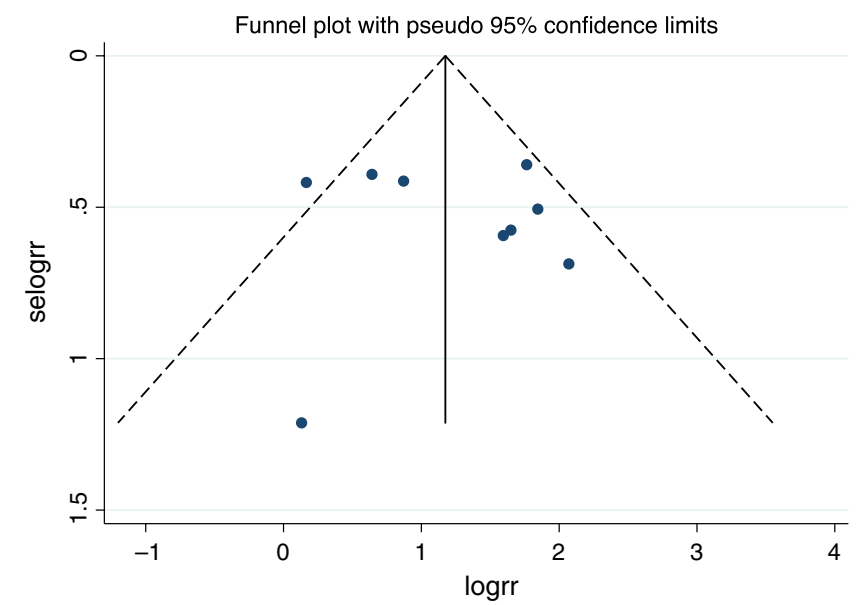

FIGURE 3 Funnel plot of fragmented QRS and major arrhythmic events. Circles represent observed published studies

noninvasive tool for risk stratification in Brugada syndrome (Morita et al., 2008). Initially, fQRS was reported to be correlated with myocardial scar and prognosis of old myocardial infarction (Das et al., 2008).
The prognostic value of fQRS was then broadened to prediction of MAE and SCD in ischemic heart disease, nonischemic cardiomyopathy, and various heart disease patients (Das \& Zipes, 2009; Das et al., 2008, 2010).

In patients with Brugada syndrome, fQRS was reported to be appear in the right precordial leads and was correlated with MAE in symptomatic patients (Morita et al., 2008). A prospective cohort study reported by Priori et al. showed that fQRS was a potential predictor of MAE in Brugada syndrome patients even without a previous history of cardiac arrest (Priori et al., 2012). The presence of fQRS correlates with increased risk in most of the studies (de Asmundis et al., 2017; Maury et al., 2013; Morita et al., 2008, 2017; Priori et al., 2012; Take et al., 2012; Tokioka et al., 2014). However, the role of fQRS has been controversial (Adler et al., 2016). Because of controversial results from previous studies, the prognostic value of fQRS in predicting MAE in Brugada syndrome had come into question (Adler et al., 2016).

In the present study, we evaluated the fQRS in patients with BrS by systemic review and meta-analysis. To our knowledge, our study is the first meta-analysis to assess the predictive value of fQRS in precordial leads $\left(\mathrm{V}_{1}-\mathrm{V}_{3}\right)$ for the development of MAE in Brugada 
syndrome patients. Our findings confirm that fQRS is associated with an increased risk of MAE up to 3-fold.

Our meta-analysis summarized all available evidence on MAE in Brugada syndrome from nine studies, a total of 2,360 patients (550 fQRS and 1,810 non-fQRS). Our study revealed that Brugada syndrome patients with $\mathrm{fQRS}$ have statistically significant increased risk of $\mathrm{MAE}$ compared to those without $\mathrm{fQRS}$ ( $\mathrm{RR}=3.36$, confidence interval $[\mathrm{Cl}]: 2.09-5.38, p<.001)$ as well as fatal arrhythmia $(\mathrm{RR}=3.09 \%$, $95 \% \mathrm{Cl}: 1.40-6.86, p=.005)$. To prove the validity of the result, we performed a sensitivity analysis by excluding one study at a time. The results are similar to the main result. This result stresses the importance of integrating fQRS into risk stratification of Brugada syndrome for SCD in clinical practice. Fragmented QRS could be considered as a possible important factor for ICD implantation in Brugada syndrome patient.

\section{5 | LIMITATION}

Our study is not without limitations. We limited fQRS to precordial leads $V_{1}-V_{3}$. There was no available reported data to examine fQRS in nonprecordial leads as a prognostic value of MAE and SCD. Different study populations and designs were included and thus might introduce potential sources of heterogeneity. However, we found no difference among exploratory subgroup analysis in European versus Japanese descendants, case-control versus cohort study design, and univariate versus multivariate analysis. We also did not demonstrate independent predictors of SCD in Brugada syndrome such as age, gender, diabetes, and hypertension because of insufficient data from included studies to perform meta-analysis in these subgroups. These factors might introduce potential sources of heterogeneity as well. Some heterogeneity exists among studies. Nonetheless, we used sensitivity analysis methods in the random-effects model and found no difference of the imputed risk ratio and its $95 \%$ confidence interval.

\section{6 | CONCLUSION}

In conclusion, our meta-analysis demonstrated that $\mathrm{fQRS}$ in precordial leads is a valuable predictor of MAE and SCD in Brugada syndrome patients. Fragmented QRS could be considered as a possible important factor for ICD implantation in Brugada syndrome patients. Further study is needed to establish its potential role in identifying the Brugada syndrome patients at highest risk of SCD.

\section{ACKNOWLEDGMENT}

None.

\section{CONFLICT OF INTEREST}

None to declare.

\section{AUTHORS CONTRIBUTION}

Pattara Rattanawong: Conception design, data interpretation, draft manuscript, corresponding. Tanawan Riangwiwat: Data acquisition, data interpretation. Narut Prasitlumkum: Data acquisition, draft manuscript. Nath Limpruttidham: Data acquisition, statistic analysis. Napatt Kanjanahattakij: Data interpretation, draft manuscript. Pakawat Chongsathidkiet: Data acquisition. Wasawat Vutthikraivit: Data interpretation. Eugene H Chung: Revise manuscript, critical reading.

\section{ORCID}

Pattara Rattanawong (iD http://orcid.org/0000-0001-9419-5854

\section{REFERENCES}

Adler, A., Rosso, R., Chorin, E., Havakuk, O., Antzelevitch, C., \& Viskin, S. (2016). Risk stratification in Brugada syndrome: Clinical characteristics, electrocardiographic parameters, and auxiliary testing. Heart Rhythm: The Official Journal of the Heart Rhythm Society, 13(1), 299-310.

de Asmundis, C., Mugnai, G., Chierchia, G. B., Sieira, J., Conte, G., Rodriguez-Manero, M., ... Brugada, P. (2017). Long-term follow-up of probands with brugada syndrome. American Journal of Cardiology, 119(9), 1392-1400.

Brugada, P., \& Brugada, J. (1992). Right bundle branch block, persistent ST segment elevation and sudden cardiac death: A distinct clinical and electrocardiographic syndrome. A multicenter report. Journal of the American College of Cardiology, 20(6), 1391-1396.

Calò, L., Giustetto, C., Martino, A., Sciarra, L., Cerrato, N., Marziali, M., ... Gaita, F. (2016). A new electrocardiographic marker of sudden death in Brugada syndrome. Journal of the American College of Cardiology, 67(12), 1427-1440.

Conte, G., de Asmundis, C., Sieira, J., Ciconte, G., Di Giovanni, G., Chierchia, G. B., ... Brugada, P. (2016). Prevalence and clinical impact of early repolarization pattern and QRS-fragmentation in high-risk patients with brugada syndrome. Circulation Journal, 80(10), 2109-2116.

Das, M. K., Maskoun, W., Shen, C., Michael, M. A., Suradi, H., Desai, M., ... Bhakta, D. (2010). Fragmented QRS on twelve-lead electrocardiogram predicts arrhythmic events in patients with ischemic and nonischemic cardiomyopathy. Heart Rhythm: The Official Journal of the Heart Rhythm Society, 7(1), 74-80.

Das, M. K., Suradi, H., Maskoun, W., Michael, M. A., Shen, C., Peng, J., ... Mahenthiran, J. (2008). Fragmented wide QRS on a 12-lead ECG: A sign of myocardial scar and poor prognosis. Circulation Arrhythmia and Electrophysiology, 1(4), 258-268.

Das, M. K., \& Zipes, D. P. (2009). Fragmented QRS: A predictor of mortality and sudden cardiac death. Heart Rhythm: The Official Journal of the Heart Rhythm Society, 6(3 Suppl), S8-S14.

Delise, P., Allocca, G., Marras, E., Giustetto, C., Gaita, F., Sciarra, L., ... Sitta, N. (2011). Risk stratification in individuals with the Brugada type 1 ECG pattern without previous cardiac arrest: Usefulness of a combined clinical and electrophysiologic approach. European Heart Journal, 32(2), 169-176.

DerSimonian, R., \& Laird, N. (1986). Meta-analysis in clinical trials. Controlled Clinical Trials, 7(3), 177-188.

Higgins, J. P., Thompson, S. G., Deeks, J. J., \& Altman, D. G. (2003). Measuring inconsistency in meta-analyses. BMJ, 327(7414), 557-560.

Maury, P., Rollin, A., Sacher, F., Gourraud, J. B., Raczka, F., Pasquie, J. L., ... Probst, V. (2013). Prevalence and prognostic role of various conduction disturbances in patients with the Brugada syndrome. American Journal of Cardiology, 112(9), 1384-1389. 
Morita, H., Kusano, K. F., Miura, D., Nagase, S., Nakamura, K., Morita, S. T., ... Wu, J. (2008). Fragmented QRS as a marker of conduction abnormality and a predictor of prognosis of Brugada syndrome. Circulation, 118(17), 1697-1704.

Morita, H., Watanabe, A., Morimoto, Y., Kawada, S., Tachibana, M., Nakagawa, K., ... Ito, H. (2017). Distribution and prognostic significance of fragmented QRS in patients with brugada syndrome. Circulation Arrhythmia and Electrophysiology, 10, 3.

Patsopoulos, N. A., Evangelou, E., \& loannidis, J. P. (2008). Sensitivity of between-study heterogeneity in meta-analysis: Proposed metrics and empirical evaluation. International Journal of Epidemiology, 37(5), 1148-1157.

Priori, S. G., Blomstrom-Lundqvist, C., Mazzanti, A., Blom, N., Borggrefe, M., Camm, J., ... Van Veldhuisen, D. J. (2015). 2015 ESC Guidelines for the management of patients with ventricular arrhythmias and the prevention of sudden cardiac death: The task force for the management of patients with ventricular arrhythmias and the prevention of sudden cardiac death of the European Society of Cardiology (ESC). Endorsed by: Association for European Paediatric and Congenital Cardiology (AEPC). European Heart Journal, 36(41), 2793-2867.

Priori, S. G., Gasparini, M., Napolitano, C., Della Bella, P., Ottonelli, A. G., Sassone, B., ... Colombo, M. (2012). Risk stratification in Brugada syndrome: Results of the PRELUDE (PRogrammed ELectrical stimUlation preDictive valuE) registry. Journal of the American College of Cardiology, 59(1), 37-45.

Probst, V., Veltmann, C., Eckardt, L., Meregalli, P. G., Gaita, F., Tan, H. L., ... Wilde, A. A. (2010). Long-term prognosis of patients diagnosed with Brugada syndrome: Results from the FINGER Brugada Syndrome Registry. Circulation, 121(5), 635-643.

Sacher, F., Probst, V., Maury, P., Babuty, D., Mansourati, J., Komatsu, Y., ... Haissaguerre, M. (2013). Outcome after implantation of a cardioverter-defibrillator in patients with Brugada syndrome: A multicenter study-part 2. Circulation, 128(16), 1739-1747.

Sakamoto, S., Takagi, M., Tatsumi, H., Doi, A., Sugioka, K., Hanatani, A., \& Yoshiyama, M. (2016). Utility of T-wave alternans during night time as a predictor for ventricular fibrillation in patients with Brugada syndrome. Heart and Vessels, 31(6), 947-956.

Stang, A. (2010). Critical evaluation of the newcastle-ottawa scale for the assessment of the quality of nonrandomized studies in meta-analyses. European Journal of Epidemiology, 25(9), 603-605.

Sterne, J. A., \& Egger, M. (2001). Funnel plots for detecting bias in metaanalysis: Guidelines on choice of axis. Journal of Clinical Epidemiology, 54(10), 1046-1055.

Take, Y., Morita, H., Toh, N., Nishii, N., Nagase, S., Nakamura, K., ... Ito, H. (2012). Identification of high-risk syncope related to ventricular fibrillation in patients with Brugada syndrome. Heart Rhythm: The Official Journal of the Heart Rhythm Society, 9(5), 752-759.

Tokioka, K., Kusano, K. F., Morita, H., Miura, D., Nishii, N., Nagase, S., ... Ohe, T. (2014). Electrocardiographic parameters and fatal arrhythmic events in patients with Brugada syndrome: Combination of depolarization and repolarization abnormalities. Journal of the American College of Cardiology, 63(20), 2131-2138.

How to cite this article: Rattanawong P, Riangwiwat T, Prasitlumkum N, et al. Baseline fragmented QRS increases the risk of major arrhythmic events in Brugada syndrome: Systematic review and meta-analysis. Ann Noninvasive Electrocardiol. 2018;23:e12507. https://doi.org/10.1111/anec.12507 